ДОМБРОВСКАЯ Анна Юрьевна - доктор социологических наук, профессор департамента политологии факультета социальных наук и массовых коммуникаций Финансового университета при Правительстве РФ (125993, Россия, г. Москва, ГСП-3, Ленинградский пр-кт, 49); доцент кафедры социально-политических исследований и технологий Института истории и политики Московского педагогического государственного университета (119991, Россия, г. Москва, ул. М. Пироговская, 1/1; an-doc@yandex.ru)

\title{
ТЕХНОЛОГИИ ФОРМИРОВАНИЯ КУЛЬТУРЫ ГРАЖДАНСКОЙ АКТИВНОСТИ МОЛОДЕЖИ В ДЕЯТЕЛЬНОСТИ ОБЩЕСТВЕННЫХ ОРГАНИЗАЦИЙ РОССИИ
}

\begin{abstract}
Аннотация. В статье анализируется репрезентация технологий ценностного воздействия в деятельности общественных объединений на формирование гражданских установок российской молодежи. На основе гибридной стратегии эмпирического исследования, включающей всероссийский массовый онлайн-опрос молодежи, глубинное интервью с лидерами и активом общественных объединений РФ, когнитивное картирование цифровых сообществ негосударственного сектора, социально-медийную аналитику с применением сервиса для мониторинга социальных медиа и анализа социальных графов цифровых групп российских общественных молодежных организаций и движений, формулируются базовые выводы о потенциале третьего сектора РФ в процессе формирования культуры гражданской активности молодого поколения. Эмпирически доказано, что сочетание существенной готовности российской молодежи к преобразованию гражданской активности в формат политического активизма и высокого потенциала эффективности технологий ценностного влияния общественных объединений и событий-триггеров, способствующих протестной мобилизации молодого поколения, обеспечивает высокую вероятность реализации сценария повышения неконвенциональной активности российской молодежи.
\end{abstract}

Ключевые слова: общественные объединения, российская молодежь, ценностное воздействие, технологии формирования гражданского активизма, культура гражданской активности, массовый онлайнопрос, глубинное интервью, когнитивное картирование, социально-медийная аналитика, анализ социальных графов

Введение. Исследование актуализируется двумя обстоятельствами, отражающими специфику гражданской активности современной российской молодежи: это более широкая по сравнению с родительским поколением вовлеченность молодых людей в гражданские и политические практики, а также высокая скорость переключения гражданской активности представителей молодого поколения в политические форматы, онлайн-стратегий - в реальные практики, конвенциональных форм активизма - в неконвенциональные формы. В условиях внешнего информационного давления и активизации внутренних внесистемных сил формируются условия для реализации эффекта стоячей волны, при котором рост протестного потенциала достигает своего максимума и актуализируется под влиянием событий-триггеров. В течение 2020 г. участились подобные «спусковые крючки» неконвенциональной активности: это дискуссия о поправках в Конституцию РФ, ограничительные меры в связи с пандемией $C O V I D-19$, дело бывшего губернатора Хабаровского края, «отравление» А. Навального, белорусский кризис. Среди таких событий особое место принадлежит электоральному циклу и транзиту власти. В условиях повышения градуса критических настроений среди российской молодежи важно выявить и проанализировать технологии, используемые общественными объединениями 
в процессе формирования гражданских установок молодежи в современной России.

Теоретическая база исследования. Культура гражданской активности как научная категория чаще всего отражается в теориях общественных движений и сводится к способности группы к проявлению организованных усилий для достижения определенной цели, обычно социальной или политической, либо для предотвращения или отмены социальных изменений ${ }^{1}$ [Deric 2011]. Концепции политической активности в Интернете Р. Полата, Ф. Ховарда и М. Паркса [Polat 2005; Howard, Parks 2012] обеспечили возможность анализа онлайн-сетевых технологий и приемов развития культуры гражданского активизма и политической активности молодежи.

Методологическая база исследования включает в себя следующие компоненты:

- социальный конструктивизм (дискурсивная психология) [Potter, Wetherell 1987], позволивший рассмотреть социальное пространство общественных объединений как смыслообразующее, предопределяющее социальные установки молодежи;

- сетевой подход (концепция сетевой культуры) [Mercer 2011; Knoke 1990; Emirbayer, Goodwin 1994; Comparing Policy... 1998], обеспечивший понимание возможностей онлайн-сетевой среды в формировании у молодого поколения культуры гражданской и политической активности;

- когнитивный подход (когнитивная карта как эмпирический инструмент политического исследования) [Толмен 1980; Harre 1992], ставший основой для интерпретации фактуальных данных глубинных интервью с лидерами общественных объединений;

- психологическое направление в постбихевиорализме [Инглхарт 2018], предопределившее способы анализа потенциала стимульного воздействия общественных объединений в зависимости от ценностного профиля их сторонников;

- основные положения в трудах российских исследователей о методологии и методике эмпирического анализа культуры социальной активности молодежи [Бродовская и др. 2019; Кафтан 2019; Шатилов 2019] и др.

Дизайн исследования. Всероссийское исследование, проведенное коллективом ученых в сентябре-октябре 2020 г., основано на комплексной стратегии, включившей массовый онлайн-опрос молодежи (1 000 респондентов в возрасте от 15 до 29 лет, репрезентация по полу, возрасту, территориальной принадлежности); глубинное интервью с молодежью - лидерами, активистами и сторонниками общественных объединений (35 информантов всех полов, различных возрастов и из разных сфер общественной активности) ${ }^{2}$; когнитивное картирование информационного потока, посвященного гражданскому активизму (530 сообщений, 12 релевантных онлайн-сообществ, механическая выборка, период - с 01.05.2020 по 01.07.2020); социально-медийный анализ (SMA)

\footnotetext{
1 Social Movements. - A Dictionary of Sociology (ed. by J. Scott, G. Marshall). Oxford: Oxford University Press. 2009.

2 Формирование выборочной совокупности информантов для глубинного интервью основывалось на принципах представленности в выборке лидеров, активистов и сторонников общественных объединений молодежи из всех основных сфер: волонтерские, благотворительные, правозащитные, феминистские, экологические, электоральные, антикоррупционные, протестные, студенческие, поисковые объединения, всего 20. Методика формирования топик-гайда подразумевала использование нескольких модулей интервью, таких как мотивация участия, структура организационных связей, онлайн-сетевые, офлайн-технологии работы объединения, взаимодействие с органами власти, с другими организациями третьего сектора.
} 
информационных потоков гражданского активизма с применением интернет-сервиса автоматизированного мониторинга социальных медиа (IQBuzz): 1000000 аккумулированных сообщений, 60 наиболее популярных социальных медиа, глубина выгрузки - период с 01.01.2020 по 01.10.2020, язык русский, геолокация - Рунет); анализ социальных графов с применением авторского ПО (60 онлайн-сетевых сообществ гражданской и политической направленности с числом подписчиков до 100000 чел.).

Результаты. Прежде всего следует отметить, что абсолютное большинство $(77,1 \%)$ опрошенной российской молодежи положительно ответили на вопрос, готовы ли они объединяться с другими людьми для совместных действий, если их идеи и интересы совпадают. Это означает, что потенциально воздействие структур третьего сектора, сегмента гражданских инициатив на современную российскую молодежь довольно высоко.

Более трети $(39,7 \%)$ молодежи РФ готовы присоединяться к гражданским инициативам по решению экологических проблем, четверть $(25,4 \%)$ - для защиты животных, более четверти $(28,7 \%)$ представителей молодого поколения демонстрируют установку на интегрирацию в деятельность общественных объединений, ориентированных на решение социально-экономических проблем. Важно подчеркнуть, что немногим менее половины $(43,2 \%)$ опрошенной российской молодежи имеют опыт участия в публичных мероприятиях, направленных на решение различных общественных проблем.

Согласно данным кластеризации базы массового опроса, значительная часть $(12,6 \%)$ молодых россиян нацелены на конфликтную стратегию гражданского активизма, сопряженную с критическим отношением к действующей власти и отказом от выполнения частью ее представителей гражданских обязанностей. Еще менее четверти $(23,4 \%)$ российской молодежи демонстрируют активную включенность в информационные потоки о социальных и политических проблемах российского общества, что сочетается с негативной оценкой ее представителей положения дел в стране.

Прагматизм и материальная выгода, правовой нигилизм, расчет на протестные акции как на «единственное эффективное средство» гражданской активности служат ведущими факторами формирования оппозиционной стратегии у лидеров и активистов общественных организаций. Высокий уровень неудовлетворенности положением дел в стране, недоверие к органам власти, давление внешних и внутренних социально-медийных потоков протестного содержания обеспечивают вовлечение рядовых членов в оппозиционно ориентированные общественные объединения.

Исходя из этого, исключительно важно проанализировать те технологии общественных объединений, которые оказывают влияние на гражданские установки российской молодежи.

Анализ стенограмм глубинных интервью с лидерами и активом российских молодежных общественных организаций, работающих в сфере экологической, правозащитной, волонтерской, благотворительной повесток, позволил сегментировать технологии формирования гражданских установок молодежи (см. табл. 1).

Анализ стенограмм глубинных интервью с лидерами и активистами экологических и правозащитных объединений показывает наличие упора в работе этих организаций на проведение массовых акций: «единственная эффективная мера решить проблему - обратить на нее внимание власти с помощью протестной акции» (лидер экологического объединения, молодой человек 26 лет); «митинги - это наше самое продуктивное средство» (активистка правозащитного объединения, девушка 19 лет). 
Таблииа 1

Типология базовых технологий формирования установок гражданского активизма российской молодежи

\begin{tabular}{|c|c|}
\hline $\begin{array}{c}\text { Критерий } \\
\text { дифференциации } \\
\text { технологии }\end{array}$ & Типы технологий \\
\hline $\begin{array}{l}\text { Дистанционные } \\
\text { технологии }\end{array}$ & $\begin{array}{l}\text { Размещение информационных постов; стримы о работе } \\
\text { общественных объединений; гражданские интернет-платформы; } \\
\text { странички известных гражданских активистов; технологии SMM для } \\
\text { «доставки» информации; социальная реклама; телефоны горячей } \\
\text { линии }\end{array}$ \\
\hline $\begin{array}{l}\text { Офлайн- } \\
\text { технологии }\end{array}$ & $\begin{array}{l}\text { Массовые акции, публичные презентации, открытые лекции } \\
\text { Фестивали национальных культур, молодежного творчества, } \\
\text { профессионального мастерства и т.п. } \\
\text { Конвейеры социальных инициатив, школы/лаборатории } \\
\text { гражданского активизма } \\
\text { Тренинги/мастер-классы (краудсорсинг, краудфандинг и т.п.) } \\
\text { Конкурсы/гранты на реализацию социальных проектов } \\
\text { молодежными командами } \\
\text { Форумы/конференции/круглые столы } \\
\text { Игровое моделирование /деловые игры, флешмобы }\end{array}$ \\
\hline
\end{tabular}

Эти тенденции формирования культуры протеста в работе общественных объединений критической направленности согласуются с результатами массового опроса молодежи РФ; в кластере «оппозиционных акторов» более 2/3 выражают убежденность в необходимости как санкционированных, так и несанкционированных акций протеста в процессе достижения целей организации.

Интересен фрагмент интервью с одним из лидеров объединения, в котором он поясняет одну из возможных мер снижения протестной активности критически ориентированных организаций/движений: «Органы власти не идут на контакт, нам не хватает взаимодействия с ними, поэтому приходится вот так обращать на себя внимание, ....а было бы по-другому, возможно, иначе действовали» (лидер правозащитного объединения, молодой человек 29 лет).

Еще одной трендовой технологией формирования культуры гражданской активности молодежи в работе общественных объединений служит использование онлайн-сетевых приемов воздействия: «Мы активно используем социальные сети для продвижения своих идей, поиска новых сторонников, делаем стримы, ссылки на странички известных общественных деятелей, активистов, активно распространяем посты о наших идеях, подогреваем к себе интерес в сети» (лидер волонтерского объединения, молодой человек 24 лет); «Я сам узнал об этой организации в сети, ...это очень действенно - минимум затрат максимум результата... так, через сети, SMM, рекламу в медиа, заходы в “дружественные" группы можно привлечь новые силы» (рядовой член студенческого объединения, молодой человек 20 лет).

Ведущим каналом формирования конструктивных гражданских установок являются социальные медиа общественных организаций и движений. Наиболее продуктивно применение новых медиа осуществляется в рамках гражданских инициатив в сфере экологии, защиты прав женщин, прочих правозащитных активностей.

Анализ социальных графов 60 наиболее популярных и имеющих большую пользовательскую аудиторию онлайн-сетевых групп - цифровых двойников 


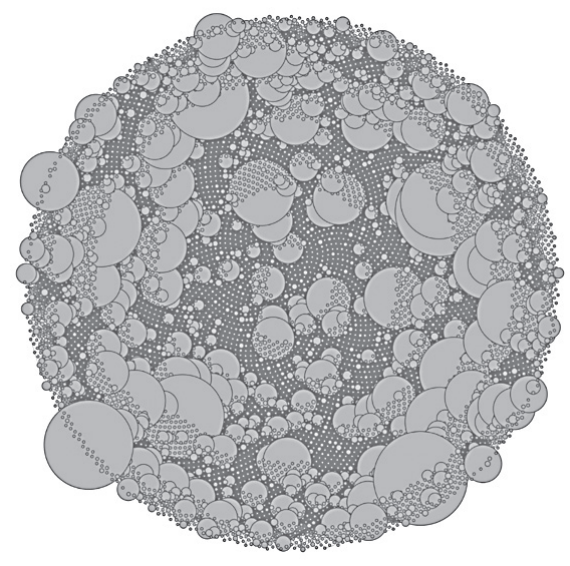

Рисунок 1. Социальный граф сообщества «Права человека»

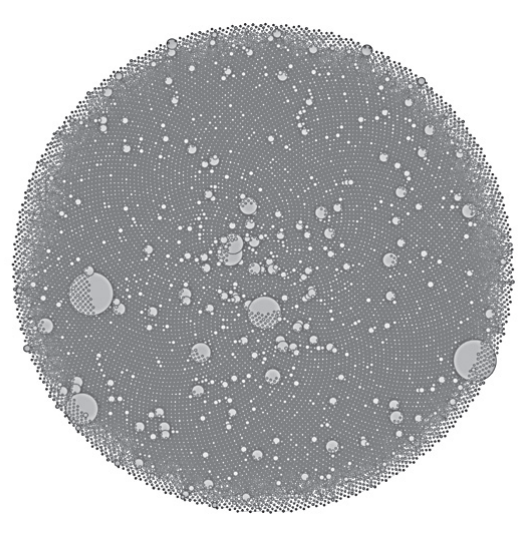

Рисунок 2. Социальный граф сообщества «Экология России»

общественных объединений показал доминирование такой технологии ценностного воздействия на гражданские установки сторонников, как микрогрупповая работа топикстартеров.

На рис. 1 показан один из графов общественных объединений, наиболее явно указывающих на технологию микрогрупповой работы («Права человека» Vk.com/propravacheloveka).

В социальном графе каждая точка означает профиль социального медиа, т.е. пользователя, участвующего в данной цифровой группе. Окружности, образуемые данными точками, - это микросообщества в составе целой группы. Согласно метрикам программного обеспечения, в анализируемой группе функционируют 92 топикстартера (микролидера) с аудиторией более 100 подписчиков. Сообщество имеет высокие показатели пользовательской активности и сплоченности. Устройство группы говорит о ее значительном потенциале мобилизации гражданских установок.

Довольно показательны для демонстрации возможностей микрогрупповой работы топикстартеров сообщества экологической направленности. На рис. 2 представлен социальный граф группы «Экология России» (Vk.com/rus_eco).

Метрики группы «Экология России» указывают на интенсивную работу 59 микролидеров с аудиторией 60 участников и более, при этом наиболее влиятельный топикстартер имеет воздействие одновременно на 348 подписчиков. Идейное единство и высокие показатели пользовательской активности микрогрупп, координируемых топикстартерами, предопределяют значительные возможности формирования социальных установок внутри наиболее сплоченных и интенсивно взаимодействующих микросообществ.

В заключение отметим, что разнообразие и действенность технологий формирования культуры гражданской активности в деятельности общественных организаций обеспечивает им большой потенциал влияния на социальную, социально-политическую сферу регионов и страны в целом. Результаты исследования показывают существование большого риска дальнейшего развития и закрепления культуры неконвенциональной гражданской активности молодежи. Усиление этого типа культуры может происходить за счет таких характеристик технологий в работе общественных объединений, как максимальный охват аудитории и актуальные форматы, обеспечивающие широкий обще- 
ственный резонанс (интерактивность, социально-медийное сопровождение, креативность формата).

В процессе социально-медийного сопровождения своей деятельности общественные объединения делают ставку на микротаргетированную работу топикстартеров, отвечающих за мобилизацию социальной активности своей пользовательской аудитории.

Существенной проблемой следует признать дефицит, испытываемый общественными объединениями, во взаимодействии с органами власти. Недостаток поддержки, конструктивного сотрудничества со стороны официальных структур действующей власти может способствовать развитию критической, неконвенциональной повестки в работе структур гражданского общества, преобразованию их гражданских инициатив в формат политического активизма, закреплению культуры неконструктивной гражданской активности.

Статья подготовлена по результатам исследований, выполненныхза счет бюджетныхсредств по государственному заданию Финуниверситету.

\section{Список литературы}

Бродовская Е.В., Домбровская А.Ю., Пырма Р.В., Азаров А.А. 2019. Специфика критического мышления российской молодежи в условиях цифровизации. - Гуманитарные науки. Вестник Финансового университета. Т. 9. № 1(37). C. 14-23.

Инглхарт Р. 2018. Культурная эволюция: как изменяются человеческие мотивации и как это меняет мир (пер. с англ. С.Л. Лопатиной; под ред. М.А. Завадской, В.В. Костенко, А.А. Широкановой; науч. ред. Э.Д. Понарин). М.: Мысль. 347 с.

Кафтан В.В. 2019. Формирование профессиональной культуры молодежи в условиях цифровой экономики: зарубежный и отечественный опыт. Гуманитарные науки. Вестник Финансового университета. Т. 9. № 1(37). С. 24-31.

Толмен Э. 1980. Когнитивные карты у крыс и человека. - Хрестоматия по истории психологии (под ред. П.Я. Гальперина, А.Н. Ждан). М.: Изд-во МГУ. C. 63-82.

Шатилов А.Б. 2019. «Мягкие» технологии российской власти по профилактике и нейтрализации экстремистских проявлений в молодежной среде в 2000-2010-е годы. - Гуманитарные науки. Вестник Финансового университета. T. 9. № 1(37). С. 32-37.

Comparing Policy Networks (ed. by D. Marsh). 1998. Buckingham: Open University Press. 226 p.

Deric Sh. 2011. Political Sociology: Oppression, Resistance, and the State. Pine Forge Press. $150 \mathrm{p}$.

Emirbayer M., Goodwin J. 1994. Network Analysis, Culture and the Problem of Agency. - American Journal of Sociology. Vol. 99. No. 6. P. 1411- 1454.

Harre R. 1992. The Second Cognitive Revolution. - American Behavioral Scientist. Vol. 36. No. 1. P. 5-7.

Howard Ph., Parks M. 2012. Social Media and Political Change: Capacity, Constraint and Consequence. - Journal of Communication. Vol. 62. No. 2. P. 359-362.

Knoke D. 1990. Political Networks. The Structural Perspective. Cambridge: Cambridge University Press. 274 p.

Mercer C. 2011. Culturelinks: Cultural Networks and Cultural Policy in the Digital Age. - Networks: The Evolving Aspects of Culture in the 21st Century (ed. by B. Cvjetičanin). Zagreb: Institute for International Relations Culturelink Network. P. 31-45. 
Polat R. 2005. The Internet and Political Participation: Exploring the Explanatory Links. - European Journal of Communication. Vol. 20. No. 4. P. 435-459.

Potter J., Wetherell M. 1987. Discourse and Social Psychology: Beyond Attitudes and Behavior. London: Sage.

DOMBROVSKAYA Anna Yur'evna, Dr.Sci. (Soc.), Professor of the Department of Political Science, Faculty of Social Sciences and Mass Communications, Financial University under the Government of the Russian Federation (49 Leningradsky Ave, GSP-3, Moscow, Russia, 125993); Associate Professor of the Chair of Social and Political Research and Technology, Institute for History and Politics, Moscow Pedagogical State University (1/1 Malaya Pirogovskaya St, Moscow, Russia, 119991; an-doc@yandex.ru)

\title{
TECHNOLOGIES FOR FORMING A CULTURE OF CIVIC ENGAGEMENT AMONG RUSSIA'S YOUTH IN THE WORKING OF PUBLIC ORGANIZATIONS
}

\begin{abstract}
The article analyzes the representation of technologies of value influence in the activities of public associations on the formation of civic attitudes of Russian youth. The analysis is based on a hybrid strategy of empirical research, including the all-Russian mass online survey of young people; in-depth interviews with leaders and activists of public associations of the Russian Federation; cognitive mapping of digital communities in the non-government sector; social media analytics using a service for monitoring social media and analyzing social graphs of digital groups of Russian public youth organizations and movements. The author formulates basic conclusions about the potential of the third sector of the Russian Federation in the process of forming a culture of civic engagement of the younger generation. The results of the survey prove that the combination of a significant readiness of Russian youth to transform civic engagement into a format of political activism, a high potential for the effectiveness of technologies of value influence of public associations and trigger events contributing to protest mobilization of the younger generation provides a high probability of the scenario of increasing unconventional activity of Russian youth.
\end{abstract}

Keywords: public unions, Russian youth, value impact, technologies for formation of civic activism, culture of civic engagement, mass online survey, in-depth interviews, cognitive mapping, social media analytics, analysis of social graphs 